DOI: $10.26907 / 2074-0239-2021-66-4-36-44$

УДК 811.161 .1

\author{
ФУНКЦИИ ВЕРБАЛЬНОГО РЯДА \\ В ГРАФИЧЕСКИХ РАССКАЗАХ ДЛЯ ДЕТЕЙ \\ (НА ПРИМЕРЕ РАССКАЗОВ Н. ОЛЕЙНИКОВА \\ ПРО МАКАРА СВИРЕПОГО)
}

(C) Александра Брыкова

\title{
FUNCTIONS OF A VERBAL PART OF GRAPHIC STORIES (BASED ON THE TEXTS OF N. OLEYNIKOV'S STORIES ABOUT MAKAR THE FIERCE)
}

\begin{abstract}
Aleksandra Brykova
The study discusses some aspects of a verbal part of the graphic stories about Makar the Fierce, as a type of a creolized text, written by N. Oleynikov and published in the Leningrad children's magazine "Yozh" ('The Hedgehog') in 1929-1931. The article shows that graphic stories as a polycode genre demonstrate special type of visual and verbal coordination so that the text of a graphic story depends on its visual part and performs structural and compensatory functions. The text makes it possible to identify the beginning and the end of the story, to expand the temporal and geographic boundaries of the plot using temporal localized and non-localized predicates (usual and repeated actions). The text also helps to make the plot constituent and rhythmic, and to create the entire image of a character (because of unmistakable references and a cinematic trick of voice-over with the help of onomatopoeic words). Moreover, the narrative structure of graphic stories for younger children has something in common with a representative and iconic type of discourse but finds more lexical and syntax complexity so that it would correspond to the children's communicative ability and, at the same time, improve their communicative competence.
\end{abstract}

Keywords: creolized text, graphic story, Makar the Fierce, N. Oleynikov, magazine "Yozh", representative and iconic type of discourse.

Предметом обсуждения в статье становится специфика организации вербального ряда одного из типов креолизованного текста - детских графических рассказов про Макара Свирепого, напечатанных Н. Олейниковым в ленинградском журнале «Еж» в 1929-1931 гг. Графические рассказы, как поликодовый жанр, обнаруживают специфическое взаимодействие вербальной и визуальной их составляющей, и анализ показывает, что текст в таком рассказе находится в подчинительной позиции относительно визуального ряда и выполняет структурную и компенсаторную функции. Он позволяет идентифицировать начало и конец рассказа, расширить пространственные и темпоральные границы хронотопа, введя туда действия как локализованные, так и не локализованные на временной оси (привычные и повторяющиеся). Также текст помогает обеспечить сюжету последовательное развертывание, ритм и целостность восприятия за счет точной референции и кинематографического приёма «озвучания» произведения, за который отвечают звукоподражательные слова. Одновременно с этим нарратив графических рассказов для детей младшего школьного возраста обнаруживает признаки репрезентативно-иконического дискурса, но не воспроизводит его, а усложняет как на лексическом, так и на синтаксическом уровнях, тем самым одновременно и отвечая коммуникативным потребностям читателей-детей, и повышая уровень их коммуникативной компетенции.

Ключевые слова: креолизованный текст; графический рассказ; Макар Свирепый; Н. Олейников; журнал «Еж»; репрезентативно-иконический дискурс.

В условиях современной коммуникации, предполагающей при передаче информации ак- тивное использование элементов невербального характера (иллюстраций, графиков, гифок и пр.), изучение негомогенных по своей символьной 
структуре текстов, которые принято называть креолизованными [Сорокин, Тарасов], или поликодовыми, становится все более актуальным как с позиций когнитивной лингвистики, так и с позиций нарративно-коммуникативного и прагматического подходов. Причем в случае с произведениями детской литературы объектом анализа становятся не только и не столько комиксы [Сонин], но и тексты, предполагающие четкое пространственное разделение визуальной и вербальной составляющей, в основе которой лежит не диалог, как в комиксах, а монолог, что заведомо усложняет принципы взаимодействия двух этих знаковых систем.

Типологически тексты подобного рода определяются в разных исследованиях с помощью различных, условно синонимичных терминов книжки-картинки (калька с английского термина picturebook) [Скаф], рассказ в картинках, графический рассказ [Корнилова]. Последний из предложенных терминов представляется нам наиболее удачным для целей данной статьи, так как он, на наш взгляд, является наиболее емким и актуализирует двойственную, визуально-вербальную, природу исследуемого объекта ${ }^{1}$.

Однако, насколько можно судить по обзору работ, в первую очередь зарубежных (см., например, [Arizpe, Style], [Hamer, Nodelman, Reimer], [Kummerling-Meibauer], [Nikolajeva, Scott, 2001] $]^{2}$, анализу текста таких произведений исследователи обычно уделяют значительно меньше внимания, чем, скажем, исследованию визуального ряда - в аспекте литературнохудожественном или педагогическом (вопросы чтения и обучения). В то время как собственно лингвистический анализ креолизованных произведений позволяет не только более точно определить их художественно-эстетическую природу,

\footnotetext{
1 Мы осознано оставляем за рамками статьи более подробное обсуждение вопроса терминологии жанра, так как его освещение не представляется необходимым для целей лингвистического анализа. То же касается и термина «креолизованный текст», конкурирующего с терминами «полимодальный текст», «поликодовый текст», о чем достаточно подробно написано в статье А. А. Бернадской [Бернадская].

${ }^{2}$ Относительно работы М. Николаевой и С. Скотт необходимо сделать отдельное замечание: в работе представлен довольно целостный анализ детских книг с картинками (picturebooks), в том числе разработан набор функций текста применительно к особенностям его взаимодействия с визуальным рядом (см. также более раннюю работу М. Николаевой и С. Скотт [Nikolajeva, Scott, 2000]). Однако это не отменяет того факта, что основное внимание авторов сконцентрировано все же на анализе литературоведческих аспектов исследуемых ими произведений.
}

но и оценить их с позиции соответствия текста когнитивным и языковым возможностям читателей-детей.

Несмотря на то, что «книжки с картинками» ожидаемо являются более привлекательными для детей, чем книжки без картинок, интуитивное предположение об их большей простоте для восприятия остается спорным, что хорошо показано, например, в работе П. Нодельмана [Nodelman], а также в работах ряда российских когнитивистов и психологов [Блинова, Щербакова], проведенных, однако, не на материале детской литературы. Анализ вербального ряда в таком случае помогает понять, какие задачи выполняет лингвистический уровень текста, находясь в случае графического рассказа в заведомо подчинительной, относительно визуального ряда, позиции, как он способствует (или не способствует) лучшему пониманию авторской - эстетической, воспитательной, развлекательной - задачи произведения. Особенно когда речь идет о произведениях, созданных в ранний советский период, историкокультурные особенности которого наложили свой отпечаток на тексты многих авторов, в том числе (а может быть, и в первую очередь) на тексты детских писателей. И графический рассказ занимал среди этих текстов не последнее место, о чем свидетельствует большое тематическое разнообразие таких рассказов, печатавшихся в советских детских журналах и нередко объединенных в серии. К наиболее популярным можно отнести рассказы 30-х гг. прошлого века про Умную Машу (выходившие в журнале для детей младшего возраста «Чиж») и Макара Свирепого (выходившие в журнале для детей старшего возраста «Еж»).

\section{Общая характеристика материала: графические особенности}

Макар Свирепый был одним из постоянных персонажей журнала «Еж» (1928-1935), обеспечивавших ему, наряду с другими постоянными персонажами, гипертекстовую связность. Прототипом Макара Свирепого стал Н. Олейников, работавший в это время главным редактором «Ежа» и нередко подписывавший свои произведения, в том числе исследуемые рассказы, псевдонимом Макар Свирепый. В качестве иллюстратора выступал А. Успенский, нарисовавший персонаж, чье портретное сходство с Н. Олейниковым легко усматривалось за счет характерного казацкого чуба.

Рассказы выходили в журнале в период с 1929 по 1931 гг. и представляли собой серию сюжетно связанных картинок, выполненных в черно-белой, графической манере и объединен- 
ных прозаическим текстом. От иллюстрированных рассказов, так же появлявшихся на страницах «Ежа», эти графические рассказы отличало то, что изображения были конституирующей частью произведения, определяющей, в том числе, и его вербальное оформление. Особенно хорошо это видно в рассказах «Макар Свирепый в Африке» (1929, № 6-7), «Новые приключения Макара Свирепого» ${ }^{3}$ (1930, № 13-24) и «Макар Свирепый в Америке» (1931, № 4-22).

Сюжеты рассказов про Макара Свирепого совмещали в себе элементы приключенческих, авантюрных и остросоциальных жанров, так как Макар боролся за благополучие рабочих с фашистами и ку-клус-клановцами. Тем примечательнее тот факт, что для иллюстрации таких сложных вопросов, пусть и данных через призму авантюрного приключения, был выбран жанр графического рассказа, впоследствии использовавшийся в советской публицистике в основном для решения более простых сюжетных и эстетических задач (классические «Книжки с картинками» Н. Радлова, рассказы детского журнала «Сверчок», те же рассказы про Умную Машу).

Анализ иллюстраций графических рассказов - их количества, формата и расположения - показывает, что усложнение тематики рассказов вело к постепенному увеличению количества изображений:

- в рассказе «Макар Свирепый в Африке»31 изображение, напечатанное на 6 листах в 2-х номерах журнала (по три листа в каждом);

- в рассказе «Новые приключения Макара Свирепого» - 34 изображения в 6 номерах журнала на 6 листах, распределенных крайне неравномерно: 20 изображений на 3 листах, 11 изображений на 2-х листах $(8+3)$ и 3 изображения на одном листе;

- в рассказе «Макар Свирепый в Америке» - целых 68 изображений в 7 номерах журнала в общем на 13 листах. Этот рассказ представляется наиболее стабильным, так как в 6-и номерах рассказ занимает по 2 листа (количество изображений варьируется от 12 до 8), а заключительная часть рассказа помещается на один лист и включает в себя 6 изображений.

Количество изображений на одной странице так же варьируется: наиболее часто встречаемым становится набор из 6 изображений одинакового формата, расположенных попарно в три ряда сверху-вниз. Реже количество изображений увеличивается до 8-ми или сокращается до 3-4-х. При этом показательно, что, если на странице

\footnotetext{
${ }^{3}$ Начиная с № 15-16 рассказ назывался просто «Приключения Макара Свирепого».
}

располагаются меньше 6 изображений, они обычно бывают неодинаковы по формату. В свою очередь, 6 изображений становятся той «золотой серединой», которая позволяет дать максимальное количество сюжетной информации, сохраняя при этом относительную детальность и четкость изображения, а также удобочитаемый размер шрифта (увеличение количества изображений до 8-ми неизменно вело к сильному сокращению размера шрифта и межстрочного интервала).

В исследуемых рассказах наблюдаются эксперименты не только с количеством изображений, но также с их размером и относительным расположением. В этом отношении особый интерес представляет первый рассказ «Макар Свирепый в Африке», где соседние изображения даны «в склейку», словно кадры кинопленки, несмотря на то что они могут иметь разную пространственную точку зрения и смещенную перспективу. Однако в последующих рассказах от этого визуально-композиционного приема отказываются, проводя четкую пространственную границу между соседними изображениями, отчасти преодолеваемую текстом, который объединяет несколько изображений в строке.

\section{Основные функции вербального ряда}

Увеличение количества изображений и, как следствие, необходимость печатать рассказ в нескольких номерах журнала отразились и на его вербальной составляющей, повысив значимость связующих элементов. В первую очередь речь идет о фразах, маркирующих завершение части рассказа / всего рассказа. Они выносились за пределы текста, оформлялись либо курсивом в скобках, либо разрядкой и были разнообразны с лексико-синтаксической и прагматической точек зрения, представляя собой директивы, комиссивы или репрезентативы: $O$ новых победах Макара в Африке читай в следуюшем номере "Ежа" [Олейников, 1929, № 6, с. $36^{4}$ ]; Продолжение следует [Олейников, 1930, № 13, с. 22]; Продолжение будет [Олейников, 1931, № 14, с. 21]; Продолжение в след. номере) [Олейников, 1931, № 4, с. 9]; Продолжение [Олейников, 1930, № 15-16, с. 16]; Конеи [Олейников, 1931, № 22, c. 17].

Однако впоследствии связующие фразы шаблонизировались: Продолжение следует; Продолжение будет; Окончание следует [Олейни-

\footnotetext{
4 Здесь и далее указаны год, номер и страница журнала «Еж», где были впервые напечатаны цитируемые рассказы. Орфография и пунктуация оригинала сохранены.
} 
ков, 1931, № 19-20, с. 25]. При этом другие графические способы обеспечения целостности, в том числе нумерация изображений или текстовых отрезков под ними, почти не использовались. Текст нумеровался только в первой части рассказа «Макар Свирепый в Америке», но в последующих частях от нумерации отказались, видимо, из-за того, что сквозная нумерация представлялась неудобной из-за большого объема, а нумерация внутри каждой части была неинформативна.

Для обеспечения структурной целостности рассказа, а также для более простого ориентирования читателя в нем использовались не только специальные маркеры части / конца рассказа, но и иные нарративные способы обозначения входа / выхода из ситуации рассказывания, соответствующие сказовой устной традиции, однако появлявшиеся непоследовательно: Было это в марте. Макар Свирепьй сказал: «Я поеду на слет в Галле» [Олейников, 1930, № 13, с. 22]; Так закончились удивительные приключения Макара Свирепого, которые сделали его знаменитым во всем мире [Олейников, 1930, № 24, с. 29].

В отдельных случаях для связи между частями рассказа, напечатанными в разных номерах журнала, использовались лексические повторы, поддержанные пунктуацией: Макар Свирепый схватил рыбу, схватил дельфина за горло и вытащил «Еж», завернуть добычу. Вдруг... (конец части - A. Б.); Вдруг (начало следующей части в новом номере журнала - А. Б.) Макар Свирепьй увидел берег [Олейников, 1930, № 13, с. 22; № 15-16, с. 16]. Подобные повторы, выполняя функцию когезии, одновременно с этим предполагали необходимость со стороны ребенка перечитать предыдущую часть рассказа, перед тем как знакомиться с новой (что имело смысл, так как журнал «Еж», изначально выходивший два раза в месяц, постепенно стал ежемесячным, а в некоторых случаях мог выпускаться сдвоенными номерами).

Сюжеты исследуемых рассказов строились с опорой на прямую хронологию, но допускали элементы ретроспекции и введение элементов внесюжетного хронотопа, предполагающего описание привычных / повторяющихся действий героев, темпорально не локализованных ${ }^{5}$. Элементы ретроспекции чаще использовались как один из способов обеспечения гипертекстовой связности всего журнала (включения рассказа в общий контекст), на что указывают ссылки на

\footnotetext{
5 Темпоральная (временная) локализация в работе понимается с опорой на работы А. В. Бондарко (см.. Бондарко, с. 210-233]).
}

имена других сквозных персонажей журнала и упоминание ранее напечатанных текстов: Но хитрый Макар вымазал внутри рупор клеем «ни взад ни вперед». Клей «ни взад ни вперед» изобрел Иван Топорышкин» [Олейников, 1929, № 7, c. 31]; А на другой день он вместе с Иваном Топорышкиным выехал в Европу. Но об этом читатели уже знают из прошлого номера «Ежа» [Там же, с. 32].

Необходимы были ретроспективные повторы и для указания на важные составляющие сюжета. В этом случае они могли носить эксплицитный характер и облекаться в форму вопросов, предполагающих прямое взаимодействие с читателем и направление его внимания: Bbl помните соль, которую наш герой взял с собой в путешествие? [Олейников, 1930, № 21, с. 15].

Реже ретроспективные вставки были необходимы для создания образа героя, мотивировки его поведения: Вдруг из реки вылез крокодил. Крокодил этот славился своей жадностью. Однажды он съел быка, овиу, воробья и потом еще полчаса гонялся за мухой [Олейников, 1929, № 6, c. 34]. То же касается и текстовых отрезков, представляющих собой описание привычных действий героя: Макар весело шагал по Африке и с восторгом читал свою статью, напечатанную в "Еже». Он никогда ничего не читал, кроме своих сочинений» [Там же]. Маркерами темпорально нелокализованного действия здесь становятся наречия времени всегда / никогда, противопоставленные временному детерминанту однажды как показателю локализации: Однажды он жарил рыбу, вдруг, илеп! Дрова провалились в море, лед подтаял под дровами [Олейников, 1930, № 13, с. 22].

Подобное построение сюжета усложняет и сам нарратив, и взаимодействие вербального и визуального рядов, так как текстовая составляющая рассказа лишь частично коррелирует с изображением, но не дублирует его, а расширяет его границы.

Внимания требует и сюжетный, темпорально локализованный, хронотоп, так как он так же обнаруживает расширение границ - временных и пространственных, в том числе за счет текстовой составляющей. Если в графических рассказах для детей младшего возраста (рассказах про Умную Машу или рассказах «Сверчка», например) сюжет чаще всего описывал незначительное происшествие, разрешение которого требовало не более нескольких часов, то действие рассказов про Макара Свирепого могло занимать несколько недель или месяцев, что объяснялось расширением пространственных границ: действия проходили в Америке и в Германии (до Германии, 
например, Макар плыл на льдине и оттуда возвращался на корабле). Маркерами хронотопа в первую очередь становятся предложно-падежные сочетания с предлогом через, указывающие на отрезок времени, необходимый для завершения того или иного действия: По сигналу все разом отпустили пальму - и Макар полетел! Через полчаса Макар был уже в редакичии [Олейников, 1929, № 7, с. 32]; Через неделю пароход подошел к Нью-Йорку [Олейников, 1931, № 4, с. 9].

Показательно, что, чем более социальным становится сюжет, тем меньше в нем фантастичности, что обнаруживается даже во временных маркерах. Так, в первом приключенческом рассказе «Макар Свирепый в Африке» Макар «долетел» (вместе с конем и жирафом) в Ленинград из Африки - как некого географически абстрактного топоса - за полчаса, так как его, словно барона Мюнхгаузена, запустили в небо с помощью пальмы. Стремительность полета подчеркивалась и на визуальном уровне, с помощью схематично расположенных в непосредственной близости друг от друга берега Африки и редакции «Ежа», разделенных только условной водной преградой (см. [Олейников, 1929, № 7, с. 32]). Во втором рассказе из Ленинграда до Германии (г. Гале, где должен был проходить международный слет пионеров) Макар несколько месяцев плыл на льдине (Пльл он месяи, пльлл два [Олейников, 1930, № 13, с. 22]), а до Америки добирался уже на корабле в течение недели.

Использование временных детерминантов с предлогом через, в зависимости от семантики конкретного временного существительного, позволяло варьировать временные границы сюжета, ускоряя или замедляя действие, одновременно с этим обеспечивая рассказу хронологическую непрерывность: Через минуту связанный сыичик лежал на полу и мычал <... . А Макар Свирепьй в очках и ичилиндре спокойно вышел из каюты [Олейников, 1931, № 4, с. 9].

Помимо предложно-падежных сочетаний с предлогом через, в качестве временных маркеров активно использовались наречия однажды / вдруг / уже / наконеи. Наречие однажды маркировало вход в сюжетный хронотоп; вдруг, в соответствии с жанром приключенческого рассказа, обозначало наиболее значимые сюжетные точки, а наречие уже фиксировало внимание на взаимосвязи узлов повествования: Однажды в редакцию явился заезжий американец и подал Макару Свирепому письмо [Там же, с. 8]; Макар Свирепьй шел по пустьнному переулку. Вдруг из-за угла показались два полисмена [Олейников, 1931, № 6, с. 20]; Чемпион уже надел на себя кожаный пояс, уже защелкали фотоаппарать, уже вся толпа, с замиранием сердия, поднялась со своих мест [Олейников, 1931, № 21, с. 31]; Наконец полищейские отстали [Олейников, 1930, № 15-16, c. 16].

Значительно реже в качестве маркеров временной локализации использовались конкретные даты и другие показатели, позволяющие более или менее точно разместить сюжет на временной оси, что можно объяснить спецификой жанра сказового, близкого к городской легенде. Даже использование дат можно оценивать не в историческом, а в экспрессивном плане, так как они обеспечивали своего рода гиперлокализацию: 8 августа 1930 года в 11 часов вечера на борту парохода «Смольный» произошло странное происшествие [Олейников, 1930, № 22-23, с. 28].

Сказовость хронотопа обнаруживается и в устойчивых маркерах типа на днях, использование которых позволяет сократить временную дистанцию между читателем и рассказываемой историей за счет актуального прошедшего: $\mathrm{Ha}$ днях редакция «Ежа» получила телеграмму из Америки. «Ура!» - крикнул секретарь, прочитав телеграмму ... <...> На следующий день весь город встречал Макара Свирепого на Ленинградском аэродроме [Олейников, 1931, № 22, с. 17].

Помимо маркеров темпоральной локализации действия, структурную целостность тексту и всему рассказу обеспечивают и классические способы текстовой связности, среди которых обнаруживаются не только местоименные повторы, что ожидаемо, но и активно используемые синонимические замены:

В левой руке Макар держал зонтик <..>. Вечером Иван Топорышкин, Даня Неусихин и Яша Миллер проводили знаменитого путешественника на пароход [Олейников, 1931, № 4, с. 9]; «Живо наверх!» - скомандовал Макар. - «A тыл?» - спросили друзья. - «Обо мне не беспокойтесь!» - ответил гордый изобретатель [Олейников, 1931, № 14, с. 21].

Как можно видеть из примеров, синонимы чаще всего используются для обозначения главного героя (допускаются также называния полным и усеченным вариантом имени с опущенным характеризующим прилагательным).

Исследования показывают (например, работа Е. С. Кубряковой о специфике детских актов референции [Кубрякова]), что как для текстов детской литературы, так и для детских устных и письменных нарративов нехарактерно использование синонимов для называния одного и того же референта, так как они могут вызывать ошибки кореференции. Это связано с не до конца усвоенными правилами референции и с не до конца осознанной конвенциональностью языкового 
знака. Именно поэтому примечательно, что в текстах исследуемых рассказов синонимические замены используются часто и обычно не ограничиваются двумя синонимами (типа полицейские / полисмены). Объясняется это, вероятно, не только усложнением нарратива, отражающим усложнение сюжета, но и наличием визуальной составляющей, которая облегчает процесс референции и кореференции ${ }^{6}$.

Помимо «структурной» функции, текст выполняет также компенсаторную и динамическую функции. Художественной особенностью приключенческих рассказов, насыщенных погонями, становится то, что изображение фиксирует физическое действие в «верхней точке его напряжения» (см., например, [Олейников, 1931, № 6, с. 20].), в то время как текст маркирует промежуточные этапы (за счет однородных глагольных предикатов - простых и составных с фазисной связкой), что позволяет избежать фрагментарности повествования: Он забежал вперед, перекинул через улииу свою веревку и стал ждать [Олейников, 1931, № 6, с. 20].

Ряды однородных членов представляют собой формы глагола практически исключительно прошедшего времени (если речь не идет о репликах прямой речи), в основном совершенного вида в конкретно-фактическом значении (предела и результата): Макар дочитал статью, оглянулся - и сразу понял, в чем дело [Олейников, 1929, № 6, с. 34]; Макар достал из кармана удочку, привязал ее к веревке и спустил в люк [Олейников, 1931, № 10, с. 19]. Реже используются формы несовершенного вида в конкретно-процессном значении: Задыхаясь и хрипя, он (крокодил - А. Б.) шел за Макаром на веревочке. Окрестные племена дрожали от ужаса [Олейников, 1929, № 6, с. 34].

В зависимости от конкретного нарратива ряды описанных однородных предикатов могут выполнять как динамическую функцию, так и функцию замедления сюжета. В первом случае динамика достигается за счет семы интенсивности в лексическом значении глагола, а также за счет использования лексических интенсификаторов: Крокодил во весь опор помчался за Макаром и разом схватил несчастную Ве-ме-ту-си-катули-хату (по-русски, Жучку) [Там же].

\footnotetext{
${ }^{6}$ Здесь нужно особо отметить, что полиграфическое оформление также отчасти работало на усложнение процесса референции, так как текст в рассказах про Макара Свирепого не коррелировал напрямую с тем изображением, под которым он располагался, а связывал несколько изображений, что требовало от читателя большей внимательности при соотнесении информации разных видов.
}

Во втором случае использование ряда однородных членов и глагольных повторов указывает на намеренное раскладывание действия на составляющие, отдаляющее результат: Они чешутся, чешутся... Вертят рулем направо, налево. Они чешутся, забыв о пленнике, о мотоцикле, обо всем на свете [Олейников, 1930, № 21, с. 15].

И в том, и в другом случае ряды однородных глагольных предикатов в количестве трехчетырех сближают исследуемые тексты с устным и письменным репрезентативно-иконическим (по терминологии К. Ф. Седова [Седов, с. 167-168]) дискурсом, встречающимся у детей младшего школьного возраста. В первую очередь на это указывает детализация физических действий героя, последовательное прописывание каждого этапа. При этом, в отличие от репрезентативно-иконического дискурса, в текстах про Макара Свирепого активно используются одиночные деепричастия и деепричастные обороты, что позволяет ранжировать действия по степени значимости, а также по показателю одновременности / неодновременности без использования временных детерминантов: Проходя мимо иуцимана, Макар не удержался и громко чихнул [Олейников, 1930, № 15-16, с. 16]; Сказав эти слова, Макар взобрался на мачту и не слезал с нее до самого Ленинграда: ему хотелось первым увидеть берега СССР [Олейников, 1930, № 24, с. 29].

Компенсаторная функция текста обнаруживается также в активном использовании звукоподражательных слов и знаменательных лексем со «звучащей» семантикой, дополненной семой интенсивности: Щелк! Хлоп! Бац! - и три льва забились на треножнике, как бабочка на булавке [Олейников, 1929, № 7, с. 30]; Бочка с треском и шумом покатилась вниз по лестнице [Олейников, 1931, № 6, с. 20]; 《Да здравствует «Еж»! заревел Макар. - «У-а-рp-ау!» - заревел тигр! [Олейников, 1929, № 6, с. 36].

В таком использовании «звучащей» лексики обнаруживается своего рода кинематографический прием, позволяющий «озвучить» (хотя бы на уровне ассоциаций, связанных с базовым перцептивным опытом читателя-ребенка) «немое» изображение, добавив сюжету большей динамичности и напряженности.

Однако наиболее примечательной особенностью исследуемого нарратива с позиции компенсаторной функции вербального ряда, на наш взгляд, является активное использование экспрессивной характеризующей лексики - существительных и прилагательных с положительной и отрицательной окраской: Макар протянул треножник навстречу кровожадным чудовищам [Олейников, 1929, № 7, с. 30]; Хитрылй Макар 
поставил над пальмой граммофон, а сам залез на пальму [Там же, с. 31]; Жирафа поднялась на дыбыл. Но великий наездник Макар Свирепьй уже сидел на спине животного [Там же]. Используется собственно экспрессивная лексика - не во вторичном значении и не суффиксальные образования, но наиболее употребительная, позволяющая резко очертить как положительные качества главного героя, так и отрицательные качества его противников.

Здесь, как и в случае с использованием однородных глагольных предикатов, можно говорить именно о компенсаторной функции текста (если опираться на понимание компенсаторности, выдвинутое М. Николаевой [Nikolajeva, Scott, 2000, c. 229-232]), так как текст позволяет уточнить характеристики предметов, внутреннее состояние героев, которое лишь частично доступно читателю через внешние признаки, изображенные на картинке. Это же объясняет и использование внутренней речи, оформленной с помощью кавычек: Вдруг Макар увидел парикмахера, который расставлял на витрине разные парики. «Еге, - подумал Макар, - на этот раз мне повезло». Он выхватил из рук парикмахера длинные усы, наклеил их на себя и бросился бежать [Олейников, 1930, № 15-16, с. 16]. Причем в большинстве случаев текст не противоречит изображению (не входит с ним в конфликт), лишь уточняя изображение на уровне психологических характеристик, данных отчасти через призму точки зрения имплицитного рассказчика ${ }^{7}$.

Использование экспрессивной лексики, в том числе лексики, описывающей качества героя, однако, не свидетельствует о психологизме исследуемых рассказов. Как это обычно бывает в детской литературе, характер героя достаточно статичен и сюжетно детерминирован: его качества проявляются через действия и только уточняются на вербальном уровне, что позволяет создать максимально целостный образ, призванный вызвать у читателей соответствующий эмоциональный отклик.

\section{Заключение}

Таким образом, исследование текстов графических рассказов про Макара Свирепого и анализ

\footnotetext{
${ }^{7}$ О частичном противоречии можно говорить только при использовании сравнительных оборотов: в тексте они появляются часто и добавляют всему рассказу образности и наглядности, необходимой читателюребенку, однако не всегда удачный выбор основания для сравнения ведет к алогичности этого образа: Леопард завизжал как поросенок и беспомощно повис на дереве [Олейников, 1929, № 6, с. 35]; Тигр как подстреленный голубь забился в воздухе [Там же, с. 36].
}

путей их взаимодействия с изображением показывает, что произведения негомогенной знаковой природы представляют собой сложное коммуникативно-эстетическое целое, в котором вербальная составляющая выполняет ряд структурных и компенсаторных функций. Текст в таких рассказах не просто заполняет сюжетные лакуны и делает повествование более динамичным, но позволяет вывести повествование за границы изображения (в хронологическом плане), обеспечить правильную референцию героев, создать необходимый образ героев и даже «наполнить немое изображение звуком».

В свою очередь, усложнение сюжета ведет к усложнению и на уровне визуального, и на уровне вербального рядов, требующему новых визуальных решений в количестве, формате и расположении картинок, в способах обеспечения структурной и сюжетной целостности рассказа. Это влечет за собой усложнение нарратива, который, пусть и обнаруживает признаки репрезентативно-конического дискурса и, как можно предположить, отвечает нарративным возможностям читателей-детей, не тождественен этому дискурсу. Различия обнаруживаются как на синтаксическом уровне, допускающем большее число полупредикативных конструкций, так и на уровне лексическом, где обнаруживается более активное использование синонимических замен как способа обеспечения кореференции, поддержанного стабильностью визуального ряда. Нарратив такого типа, хоть и возникает по причинам в первую очередь литературно-художественным, опосредованно способствует формированию более высокого уровня коммуникативной компетенции читателей-детей, осознанию конвенциональности языкового знака и, как следствие, стилистических возможностей языка.

\section{Список литературы}

Бернадская A. A. К проблеме «креолизации» текста: история и современное состояние // Известия Уральского государственного педагогического университета. Лингвистика. 2000. № 3. С. 104-110.

Блинова Е. Н., Щербакова О. В. Когнитивные механизмы понимания вербальных и иконических текстов // Психологический журнал. 2021. №1. (Т. 42). С. 66-79.

Бондарко A. В. (отв. ред.) Теория функциональной грамматики: Введение. Аспектуальность. Временная локализованность. Таксис. Ленинград: Наука, 1987. 348 с.

Корнилова В. В. Детские иллюстрированные журналы в художественной жизни Петербурга XIX-п.П. $\mathrm{XX}$ века. Типология и эволюция: автореф. дис. ... канд. иск. наук: СПб., 2002. 30 с. 
Кубрякова E. C. Специфика актов референции в детской речи // Детская речь: проблемы и наблюдения: Межвуз. сб. науч. тр. / Отв. ред. С. Н. Цейтлин. Ленинград: ЛГПИ, 1989. С. 4-13.

Олейников Н. Макар Свирепый в Америке // Еж: Ежемесячный журнал для детей младшего школьного возраста. 1931. № 4. С. 8-9; № 6. С. 20-21; № 10 . C. 18-19; № 14. C. 20-21; № 19-20. C. 24-25; № 21 . С. 31-32; № 22. C. 17.

Олейников Н. Макар Свирепый в Африке // Еж: Ежемесячный журнал для детей младшего школьного возраста. 1929. № 6. С. 34-36; № 7. С. 30-32.

Олейников Н. Новые приключения Макара Свирепого // Еж: Ежемесячный журнал для детей младшего школьного возраста. 1930. № 13. С. 22; № 15-6. С.16; № 17-18. C. 10 ; № 21. C. 15; № 22-23. С. 28 ; № 24. С. 29.

Седов К. Ф. Онтопсихолингвистика. Становление коммуникативной компетенции человека. М.: Лабиринт, 2008. 318 с.

Скаф $M$. Комикс и книжка-картинка: границы визуально литературных жанров // Детские чтения. 2016. №2 (T. 10) C. 285-303.

Сонин $A$. Г. Комикс как знаковая система: психолингвистическое исследование (на материале франкоязычных комиксов): дис. ...канд. филол. наук: Барнаул, 1999. $236 \mathrm{c.}$

Сорокин Ю. А., Тарасов Е. Ф. Креолизованные тексты и их коммуникативная функция // Оптимизация речевого воздействия / отв. ред. Н. А. Безменова, М.: Наука, 1990. С. 180-186.

Arizpe E., Style M. Children Reading Picturebooks. London and New York: Routledge, 2016. 256 p.

Hamer N., Nodelman P., Reimer M. More Words about Pictures: Current Research on PictureBooks and Visual/Verbal Texts for Young People. New York and London: Routledge, 2017. 244 p.

Kummerling-Meibauer B. The Routledge Companion to Picturebooks. New York: Routledge, 2018. 546 p.

Nikolajeva M., Scott C. How Picturebooks work. New York and London: Garland Publishing, 2001. 308 p.

Nikolajeva M., Scott C. The Dynamic of Picturebook Communication // Children's Literature in Education. No. 4. Vol. 31. 2000. pp. 225-239.

Nodelman P. Decording the Images: How Picture Books Work // Understanding Children's Literature: Key essays from the International Companion Encyclopedia of Children's Literature. New York: Taylot \& Francis eLibrary, 2002, pp. 128-139.

\section{References}

Arizpe, E., Style, M. (2016). Children Reading Picturebooks, 256 p. London, New York, Routledge. (In English)

Bernadskaia, A. A. (2000). K probleme "kreolizatsii" teksta: istoriia i sovremennoe sostoianie [To the Problem of Text "Creolization": History and Modern State]. Izvestiia Ural'skogo gosudarstvennogo pedagogicheskogo universiteta. Lingvistika, No. 3, pp. 104-110. (In Russian)

Blinova, E. N., Shcherbakova, O. V. (2021). Kognitivnye mekhanizmy ponimaniia verbal'nykh $i$ ikonicheskikh tekstov [Cognitive Mechanisms of Understanding of Verbal Texts and Infographics]. Psikhologicheskii zhurnal, No. 1, (Vol. 42), pp. 66-79. (In Russian)

Bondarko, A. V. (ed.) (1987). Teoriia funktsional'noi grammatiki: Vvedenie. Aspektual'nost'. Vremennaia lokalizovannost'. Taksis [Theory of the Functional Discourse Grammar: Introduction. Aspectuality. Temporal Localization. Taxis]. 348 p. Leningrad, Nauka. (In Russian)

Hamer, N., Nodelman, P., Reimer, M. (ed.) (2017). More Words about Pictures: Current Research on Picture Books and Visual/Verbal Texts for Young People. 244 p. New York, London, Routledge. (In English)

Kornilova, V. V. (2002). Detskie illiustrirovannye zhurnaly $v$ khudozhestvennoi zhizni Peterburga XIX-p.p. $X X$ veka. Tipologiia $i$ evoliutsiia: avtoref. dis. ... kand. isk. nauk [Children's Illustrated Magazines in Art Life of Petersburg in the $19^{\text {th }}$-the Beginning of the $20^{\text {th }}$ Centuries: Doctoral Thesis Abstract]. St. Petersburg, 30 p. (In Russian)

Kubriakova, E. S. (1989). Spetsifika aktov referentsii $v$ detskoi rechi [On Some Aspects of Acts of Reference in Children's Speech]. Detskaia rech': problemy i nabliudeniia: Mezhvuz. sb. nauch. tr. / ed. by S. N. Tseitlin. Leningrad, LGPI, pp. 4-13. (In Russian)

Kummerling-Meibauer, B. (ed.) (2018). The Routledge Companion to Picturebooks. 546 p. New York, Routledge. (In English)

Nikolaeva, M., Scott, C. (2001). How Picturebooks Work. 308 p. New York, London, Garland Publishing. (In English)

Nikolaeva, M., Scott, C. (2000). The Dynamic of Picturebook Communication. Children's Literature in Education, No. 4, Vol. 31, pp. 225-239. (In English)

Nodelman, P. (2002). Decoding the Images: How Picture Books Work. Understanding Children's Literature: Key Essays from the International Companion Encyclopedia of Children's Literature. New York, Taylot \& Francis e-Library, pp. 128-139. (In English)

Oleinikov, N. (1931). Makar Svirepyi v Amerike [Makar the Fierce in America]. Ezh: Ezhemesiachnyi zhurnal dlia detei mladshego shkol'nogo vozrasta, No. 4, pp. 8-9; No. 6, pp. 20-21; No. 10, pp. 18-19; No. 14, pp. 20-21; No. 19-20, pp. 24-25; No. 21, pp. 31-32; No. 22, p. 17. (In Russian)

Oleinikov, N. (1929). Makar Svirepyi v Afrike [Makar the Fierce in Africa]. Ezh: Ezhemesiachnyi zhurnal dlia detei mladshego shkol'nogo vozrasta, No. 6, pp. 34-36; No. 7, pp. 30-32. (In Russian)

Oleinikov, N. (1930). Novye prikliucheniia Makara Svirepogo [Makar the Fierce's New Adventures]. Ezh: Ezhemesiachnyi zhurnal dlia detei mladshego shkol'nogo vozrasta, No. 13, p. 22; No. 15-16, p.16; No. 17-18, p. 10 ; No. 21 , p. 15 ; No. $22-23$, p. 28 ; No. 24 , p. 29 . (In Russian)

Sedov, K. F. (2008). Ontopsikholingvistika. Stanovlenie kommunikativnoi kompetentsii cheloveka [Ontopsycholinguistica: Developing of Human's Communicative Competence]. 318 p. Moscow, Labirint. (In Russian) 
Skaf, M. (2016). Komiks i knizhka-kartinka: granicy vizual'no-literaturnyh zhanrov [Komics and Picturebooks: The Boundaries of Visual and Literature Genres]. Detskie chteniia, No. 2, Vol. 10, pp. 285-303. (In Russian)

Sonin, A. G. (1999). Komiks kak znakovaia sistema: psikholingvisticheskoe issledovanie (na materiale frankoiazychnykh komiksov): dis. ...kand. filol. nauk [Comics as a Symbol System: Psycholinguistic Research (with References to French Comics): Doctoral Thesis]. Barnaul, 236 p. (In Russian)

Sorokin, Yu. A., Tarasov, E. F. (1990). Kreolizovannye teksty $i$ ikh kommunikativnaia funktsiia [Creolized Texts and Their Communicative Functions]. Optimizatsiia rechevogo vozdeistviia. Ed. by N. A. Bezmenova. Pp. 180-186. Moscow, Nauka. (In Russian)

The article was submitted on 19.10.2021

Поступила в редакцию 19.10.2021

Brykova Aleksandra Andreevna,

Ph.D. in Philology,

Assistant Professor,

Saint-Petersburg State University,

7-9-11 Universitetskaya Emb.,

St. Peterburg, 199034, Russian Federation. a.brykova@spbu.ru 